Conclusion: Sustained clinical remission was observed in most patients with SIIA treated with canakinumab for up to 7 years, with no new or unexpected adverse events reported.

Disclosure of Interests: Ekaterina Alexeeva Grant/research support from: Roche, Pfizer, Centocor, Novartis, Speakers bureau: Roche, Novartis, Pfizer., Elizaveta Krekhova: None declared, Tatyana Dvoryakovskaya: None declared, Ksenia Isaeva: None declared, Aleksandra Chomakhidze: None declared, Evgeniya Chistyakova: None declared, Olga Lomakina: None declared, Rina Denisova: None declared, Anna Mamutova: None declared, Anna Fetisova: None declared, Marina Gautier: None declared, Dariya Vankova: None declared, Meyri Shingarova: None declared, Ivan Kriulin: None declared, Alina Alshevskaya: None declared, Andrey Moskalev: None declared

DOI: 10.1136/annrheumdis-2020-eular.5476

\section{AB0972 DEVELOPMENT OF THE PARENT VERSION OF THE JUVENILE ARTHRITIS DISEASE ACTIVITY SCORE CUT- OFFS FOR MODERATE AND HIGH DISEASE ACTIVITY STATES IN JUVENILE IDIOPATHIC ARTHRITIS IN A LARGE MULTINATIONAL PATIENT SAMPLE}

I. Avrusin $^{1,2}$, R. Naddei ${ }^{3}$, F. Ridella ${ }^{2}$, G. Januskeviciute ${ }^{4}$, M. Kostik ${ }^{1}$, B. Whitehead ${ }^{5}$, R. Gallizzi ${ }^{6}$, E. Smolewska ${ }^{7}$, S. Pastore ${ }^{8}$, P. Hashkes ${ }^{9}$, J. F. Swart ${ }^{10}$, N. Ruperto ${ }^{2}$, A. Ravelli ${ }^{2,11}$, A. Consolaro ${ }^{2,11}$ on behalf of Pediatric Rheumatology International Trials Organization. ${ }^{1}$ Saint Petersburg State Pediatric Medical University, Saint Petersburg, Russian Federation; ${ }^{2}$ Istituto Giannina Gaslini, Genoa, Italy; ${ }^{3}$ Policlinico Federico II di Napoli, Naples, Italy; ${ }^{4}$ Klaipeda Children Hospital, Klaipeda, Lithuania; ${ }^{5}$ Queensland Children's Hospital, South Brisbane, Australia, Australia; ${ }^{6}$ University of Messina, Messina, Italy; ${ }^{7}$ Medical University of Lodz, Lodz, Poland; ${ }^{8}$ IRCCS Burlo Garofolo, Institute for Maternal and Child Health, Trieste, Italy; ${ }^{9}$ Shaare Zedek Medical Center, Jerusalem, Israel; ${ }^{10}$ Wilhelmina Kinderziekenhuis, Utrecht, Netherlands;

${ }^{11}$ University of Genoa, Genoa, Italy

Background: Measurement of disease activity level is of pivotal importance in the care of patients with juvenile idiopathic arthritis (JIA). According to the most recent requirements, both, parent's and children's perception should be taken into account while evaluating the disease course and assessing effectiveness of therapy. Therefore, a new disease activity evaluation tool, based only on parent assessment of the outcome, is under development and named Parent Juvenile Arthritis Disease Activity Score (parJADAS) [1].

Objectives: The aim of this study is to develop the parJADAS cut-off values of moderate disease activity (MDA) and high disease activity (HDA) in JIA patients. Methods: The parJADAS (score range $0-40$ ) is the sum of 4 values: 1) parent's assessment of disease activity on a 21-numbered circle 0-10 VAS; 2) assessment of pain intensity on a 21-numbered circle 0-10 VAS; 3) proxy assessment of joint disease up to a maximum of 10 joints; 4) assessment of morning stiffness (MS) on a Likert scale, ranging from no MS (0 points) to $>2$ hours of MS (10 points). The study dataset is composed of 2,412 patients with JIA, seen in 3389 visits with parJADAS available, enrolled in the the multinational registry PharmaChild, assessing the long-term safety of treatment of children with JIA. At each visit, subjects were subjectively rated as being in inactive disease, low disease activity, MDA, or HDA by the attending physician. For each patient, only one visit per disease state was retained.

To identify the cut-offs the following methods were implemented: 1) Mapping: the $25^{\text {th }}$ percentile value of the parJADAS in patients having MDA or HDA, respectively, was calculated; 2) Youden Index: Youden Index (J) identifies the maximum potential effectiveness of the biomarker through the receiver operating characteristic (ROC) curve analysis; 3) Max agreement: The analysis of agreement was based on kappa statistics, which assesses the agreement beyond chance between 2 dichotomous ratings. The first rating was obtained using all possible parJADAS values as hypothetical test criteria; to obtain the second rating, the categorical ratings of each attending physician were dichotomized and were coded as 0 or 1 .

Results: Preliminary cut-off values for parJADAS with sensitivity and specificity are presented in the table.

\begin{tabular}{cccccccc}
\hline & 25th centile & Youden Index & Kappa & Mean & Sensitivity & Specificity & AUC \\
\hline MDA & 6 & 5 & 9 & 7 & 73.4 & 82.0 & 0.853 \\
HDA & 14.8 & 11 & 18.5 & 15 & 71.2 & 87.6 & 0.892 \\
\hline
\end{tabular}

Conclusion: Tentative cut-off values for classifying the states of MDA and HAD using parJADAS were calculated. The obtained values will be tested in the validation analysis. Once validated the cut-offs are ideally suited to identify subjects at risk of disease flare when remotely monitored with the parJADAS.

\section{References:}

[1] Ridella F., et al. Ann Rheum Dis, volume 78, supplement 2, year 2019, page A1434.

Acknowledgments: We wish to thank all researchers and patients participating in the PharmaChild registry

Disclosure of Interests: Ilia Avrusin: None declared, Roberta Naddei: None declared, Francesca Ridella: None declared, Giedre Januskeviciute: None declared, Mikhail Kostik: None declared, Ben Whitehead: None declared Romina Gallizzi: None declared, Elzbieta Smolewska: None declared, Ser ena Pastore: None declared, Philip Hashkes: None declared, Joost F. Swart None declared, Nicolino Ruperto Grant/research support from: Bristol-Myers Squibb, Eli Lily, F Hoffmann-La Roche, GlaxoSmithKline, Janssen, Novartis Pfizer, Sobi (paid to institution), Consultant of: Ablynx, AbbVie, AstraZeneca-Medimmune, Biogen, Boehringer Ingelheim, Bristol-Myers Squibb, Eli Lily, EMD Serono, GlaxoSmithKline, Hoffmann-La Roche, Janssen, Merck, Novartis, Pfizer, R-Pharma, Sanofi, Servier, Sinergie, Sobi, Takeda, Speakers bureau: Ablynx, AbbVie, AstraZeneca-Medimmune, Biogen, Boehringe Ingelheim, Bristol-Myers Squibb, Eli Lily, EMD Serono, GlaxoSmithKline, Hoffmann-La Roche, Janssen, Merck, Novartis, Pfizer, R-Pharma, Sanofi, Servier, Sinergie, Sobi, Takeda, Angelo Ravelli: None declared, Alessandro Consolaro Grant/research support from: Pfizer Inc., AlfaSigma, Speakers bureau: AbbVie

DOI: 10.1136/annrheumdis-2020-eular.5803

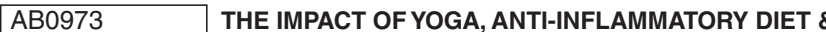 SELF MONITORING IN CHILDREN WITH RHEUMATIC DISEASES}

\section{B. Pandya ${ }^{1} .{ }^{1}$ Dev Children's Hospital, Pediatric Department, Rajkot, India}

Background: There is growing evidence of positive effects of yoga, special diet and an internet-based model of self-monitoring in adults with rheumatic diseases in various small scale independent studies. These studies have shown improvement in disease activity, symptom relief, quality of life, mental health issues and social life and thereby optimizing the disease management in a holistic way.

Objectives: The present study was designed to investigate the combined effects of yoga, anti-inflammatory diet and self monitoring in children with chronic rheumatic diseases.

Methods: In the clinical study, a total of 22 children aged more than 8 years with newly diagnosed rheumatic disease were enrolled. Depending on their consent they were divided into two groups; 1) experimental group and 2) control group. Experimental and Control Group $(\mathrm{n}=22)$

All 22 participants were advised every month follow up for the next 4 months. Baseline disease activity and damage scores were calculated for all.

Experimental Group ( $n=14)$ Three different printed materials were given

1. Pictures of "Yoga Ashnas" with explanation in their understandable language

2. Pictures of foods under two headings: 1) beneficial and 2)harmful

3. Self monitoring kit: Disease and medicines information leaflets and simplified pictorial

version of disease specific monitoring and damage scores

$\checkmark$ All 14 participants were enrolled to a single time yoga training session under a guidance of an experienced yoga teacher.

$\checkmark$ All are advised 45 minutes yoga every day at home.

$\checkmark$ All are put on strict diet chart.

$\checkmark$ All should read the material and calculate their disease score/s every time

before their next visit. Table:

\begin{tabular}{lcc}
\hline Table A: Characteristics & $\begin{array}{c}\text { Experimental group } \\
(\mathrm{n}=14)\end{array}$ & $\begin{array}{c}\text { Control group } \\
(\mathrm{n}=8)\end{array}$ \\
\hline Median age & 12.8 years & 11.2 years \\
Males & $5(35.71 \%)$ & $3(37.5 \%)$ \\
Females & $9(64.28 \%)$ & $5(62.5)$ \\
Juvenile Systemic Lupus Erythematosus (JSLE) & $2(14.28 \%)$ & $2(25 \%)$ \\
Juvenile Dermatomyositis (JDM) & $2(14.28 \%)$ & $1(12.5 \%)$ \\
Juvenile systemic sclerosis (JSSc) & $1(7.14 \%)$ & $2(25 \%)$ \\
Mixed connective tissue disease (MCTD) & $2(14.28 \%)$ & 0 \\
Enthesitis related arthritis (ERA) & $3(21.42 \%)$ & $1(12.5 \%)$ \\
Polyarticular Juvenile Idiopathic Arthritis (PJIA) & $4(28.57 \%)$ & $2(25 \%)$ \\
\hline
\end{tabular}

